\title{
Deficiência Auditiva: Aprendendo a Ter e a Conviver
}

MONOGRAFIA

\section{DEPARTAMENTO DE PSICOLOGIA}

PROGRAMA DE PÓS-GRADUAÇÃO

RIO DE JANEIRO, 29 DE ABRIL DE 2011. 
Pontificia Universidade Católica DO RIO DE JANEIRO

DEPARTAMENTO DE PSICOLOGIA

Curso de Especialização em Psicologia e Saúde

Maíra Lima Andrade

Deficiência

Auditiva:

Aprendendo a Ter e a Conviver

Monografia apresentada ao Programa de Pós-Graduação em Psicologia da PUC-Rio como requisito parcial para obtenção do título de Especialista em Psicologia e Saúde. Aprovada pela Comissão Examinadora abaixo assinada.

Professor Orientador: Mônica Campioli

Elizabeth Ribeiro

Rio de Janeiro 29 de abril de 2011. 
Dedico esta monografia aos meus pais pelo grande incentivo e investimento, por acreditarem no meu potencial 


\section{Agradecimentos}

Agradeço à Deus por estar sempre presente na minha vida, que me protege em todos os momentos da minha vida e me dá forças para superar os momentos de aflição e angústia.

À minha família ao apoio.

Aos meus pais, Fátima e Ramon, pelo incentivo e credibilidade.

Ao meu namorado, Flávio, pela atenção, compreensão e apoio.

À minha prima Maria Claudia pela dedicação e colaboração.

Às minhas amigas Bianca, Eduarda e Luana pela colaboração e apoio.

À equipe do Centro de Referencia em Saúde Auditiva pelo companheirismo e apoio.

Aos meus chefes Dr. Ramon e Dr. Everton pela oportunidade e confiança.

Às mães do grupo pelo aprendizado.

À minha orientadora Mônica pelo carinho, dedicação e paciência. 


\section{SUMÁRIO}

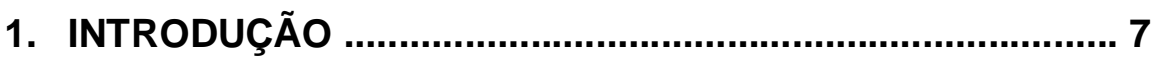

2. DESCOBRINDO A DEFICIÊNCIA AUDITIVA........................ 9

Princípios Básicos da Deficiência Auditiva........................9

O Diagnóstico da Deficiência Auditiva..............................10

2.1.1 O Processo Diagnóstico...................................................... 11

2.1.2 O Recebimento do Diagnóstico pelos Familiares............ 14

Os Prognósticos na Deficiência Auditiva............................ 16

3. RECEBENDO UM PORTADOR DE DEFICIENCIA AUDITIVA... 19

O Estigma de um Surdo........................................................ 19

Expectativas e Sentimentos dos Familiares frente a Deficiência

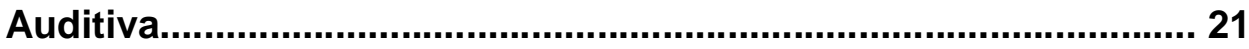

A Comunicação do Portador de Deficiência Auditiva.............. 24

- Desenvolvimento da Linguagem na Criança Portadora de

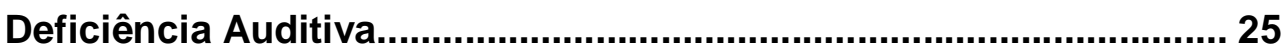

O Papel da Família no Processo de Desenvolvimento da Linguagem e Comunicação............................................................... 26

4. O SUPORTE PROFISSIONAL AOS FAMILIARES DA CRIANÇA

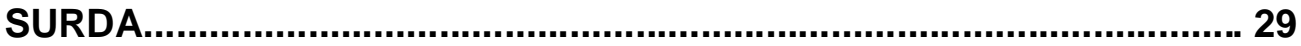

O Grupo como Suporte................................................................. 29

Grupo de Acolhimento: “Aprendendo a ser e a conviver"........ 32

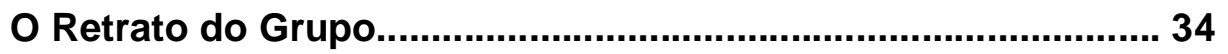

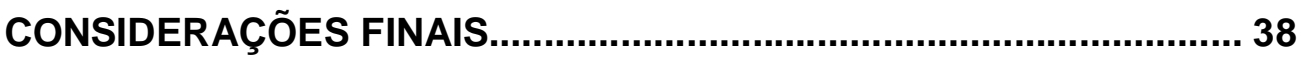

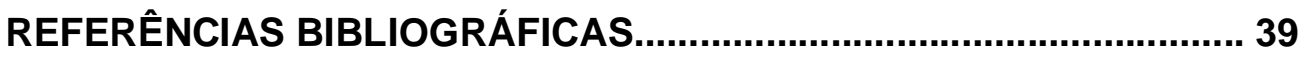




\section{Resumo}

Este estudo aborda a criança portadora de deficiência auditiva e seu contexto familiar. A criança portadora de deficiência auditiva nos primeiros meses de vida é privada de estimulação sonora no período mais importante no desenvolvimento, e consequentemente, poderá apresentar alterações emocionais, sociais e lingüísticas.

No intuito de possibilitar as famílias um meio de orientação, elaboração e compreensão frente à deficiência auditiva deu-se início a uma dinâmica grupal, no qual os familiares pudessem compartilhar dúvidas, questionamentos, sentimentos e conhecimento.

Os exemplos que ilustram tal prática tiveram como cenário o Centro de Referencia em Saúde Auditiva de Barra Mansa, através de um trabalho realizado no Grupo Aprendendo a ter e a conviver com um deficiente auditivo. O grupo era formado pelos familiares da criança, no qual foi um processo identificador de experiências.

\section{Palavras chave:}

Criança, deficiente auditiva, família, exames, diagnóstico, surdez. 
"Amar o próximo como amamos a nós mesmo significaria então respeitar a singularidade de cada um, o valor de nossas diferenças, que enriquecem o mundo que habitamos em conjunto e assim o tornam um lugar mais fascinante e agradável, aumentando a cornucópia de suas promessas". (Zygmund Bauman) 


\section{INTRODUÇÃO}

A audição pode ser considerada como uma capacidade de extrema importância para a comunicação entre pessoas, garantindo a participação na sociedade em que vivemos.

Quando existe uma deficiência auditiva, o que ocorre na grande maioria dos casos é um isolamento dos indivíduos que a apresentam, sendo que estes muitas das vezes são vistos como incapazes de desempenhar determinadas funções devido à presença desta deficiência.

Nos primeiros anos de vida, a criança portadora de deficiência auditiva apresenta dificuldades quanto à comunicação, pois pais, familiares e pessoas do convívio ainda não são capazes de realizar a compreensão dos desejos da criança. Porém, esta dificuldade, tende com o tempo a melhorar através da evolução do tratamento. O processo de aceitação da família também é fundamental para o desenvolvimento da criança diante sua deficiência. É na família que ocorre de maneira efetiva o processo de aprendizado da comunicação da criança.

Desta forma, este trabalho tem como objetivo apresentar um grupo de pais num Centro de Referencia Auditiva, como forma de identificação perante a deficiência.

O primeiro capítulo destinará sobre a deficiência auditiva, seus conceitos básicos, tais como, o processo de diagnóstico e o recebimento do diagnóstico pelos familiares. Alguns sinais de comportamento da criança podem gerar nos pais e familiares uma suspeita de perda de audição. A partir dessa perspectiva os pais buscam a ajuda de um profissional para a identificação das causas. $O$ diagnóstico é realizado através de vários exames, no qual é essencial o investimento dos pais e da criança. Pois diante da confirmação do diagnóstico, os familiares tendem a apresentar alguns sentimentos, tais como, medo, incapacidade e isolamento.

O segundo capítulo articulará o recebimento de um portador de deficiência auditiva frente à posição social e familiar. Historicamente a posição do surdo não seria a mesma de um ser humano, pelo fato, do surdo não apresentar a fala e pela incapacidade no aprendizado. Perante, o estereótipo que o surdo carrega, muitos pais ao saberem da chegada de uma criança, deficiente auditiva, defrontam com a frustração. Experienciam a perda dos sonhos e vivenciam o medo diante a deficiência. A família vai precisar se reorganizar para receber um 
deficiente, no qual vão se exigir algumas habilidades para lidar com as mudanças. A comunicação é uma das formas de interação entre as famílias e a criança.

No terceiro capítulo abordará o conceito de um grupo e seus teóricos. Como a dinâmica grupal é importante para os familiares de um portador de deficiência auditiva. O grupo proporcionará informações, experiências, sentimentos e atitudes em relação a família e suas crianças. Através do processo grupal, os familiares têm a oportunidade de estarem e conversarem com pessoas que estão vivenciando situações semelhantes, no qual identificações e sentimentos de solidariedades são apresentados. 


\section{DESCOBRINDO A DEFICIÊNCIA AUDITIVA}

A deficiência auditiva, conhecida como surdez, consiste na perda parcial ou total da capacidade de ouvir, isto é, um indivíduo que apresente um problema auditivo. É considerado surdo todo indivíduo cuja audição não é funcional no diadia, e considerado parcialmente surdo todo aquele cuja capacidade de ouvir, ainda que deficiente, é funcional com ou sem prótese auditiva. (Goldefeld, 1998).

\subsection{Princípios Básicos da Deficiência Auditiva}

A deficiência auditiva pode ocorrer pelo comprometimento das vias auditivas em três diferentes níveis ou locais, sendo o Sistema Condutivo, no qual a perda é causada por problemas no ouvido externo ou no ouvido médio, como rolha de cera, otite externa, otite média, perfuração timpânica, este tipo de perda auditiva pode ser tratado na maioria das vezes com medicamentos ou cirurgias.

No Sistema Neurossensorial, a perda causada pelo problema no ouvido interno e/ou no nervo vestíbulo coclear, podem ser divididas quanto a sua causa (etiologia), em genéticas ou adquiridas; não respondem a tratamentos clínicos ou cirúrgicos convencionais, sendo utilizado quando indicados, os aparelhos de amplificação sonora individuais (prótese auditiva) e, em casos selecionados, os implantes cocleares.

No Sistema Nervoso Central, a perda causada por problemas no tronco encefálico e/ou cérebro, como tumores e doenças neurológicas que acometam as vias auditivas centrais. (Santos; Martinho 2005)

De acordo com Santos e Martinho (2005), estima-se que de $35 \%$ a $50 \%$ de todas as perdas auditivas que se instalam precocemente sejam de origem genética. $O$ desenvolvimento do ouvido interno e das vias auditivas centrais depende da interação adequada entre centenas de genes e também do meio ambiente intra e extra-uterina. Este é um mecanismo bastante complexo, conhecido como herança multifatorial.

A deficiência auditiva adquirida pode ocorrer durante a gestação, durante o nascimento ou após este. As causas mais comuns no período pré-natal são as infecciosas (citomegalovírus, toxoplasmose, rubéola, sífilis, herpes); o uso de medicações inapropriadas durante a gravidez; ou ainda uma doença materna como diabetes ou alterações do sistema cardiovascular. Durante o parto, ou logo após período peri-natal podem ocorrer complicações que levem a uma 
diminuição de oxigenação do feto ${ }^{1}$ ou ainda uma incompatibilidade entre o tipo sanguíneo ${ }^{2}$ da mãe e do feto, que pode levar entre outros problemas a deficiência auditiva.

Para os autores no período pós-natal, uma série de problemas pode causar a deficiência auditiva. Entre eles estão as infecções (meningites, otites); o uso de medicações tóxicas para o ouvido interno (medicamento otóxicos); o trauma craniano com lesão de estruturas auditivas; a exposição a ruídos muito intensos, como bombas ou mesmo música muito alta (trauma acústico). E há também incidências de deficiência auditiva em crianças prematuras, que permanecem internados em Unidades de Terapia Intensiva, no qual a criança fica exposta há ruídos constantes produzidos por monitores, por respiradores e pela movimentação da equipe medica, podendo assim potencializar a perda auditiva dos bebes. Além disso, muitos medicamentos usados no período neonatal sabidamente têm efeito tóxico sobre o sistema auditivo de recémnascidos. Entre elas destacam-se antibióticos e diuréticos de uso constante.

No que se refere à classificação das deficiências auditivas quanto ao grau, às alterações auditivas podem ser classificadas: Leve (perda auditiva de 25 a 40 $\mathrm{dB}$ ), Moderada (perda auditiva 41 a $70 \mathrm{~dB}$ ), Severa (perda auditiva de 71 a 90 dB), Profunda (perda auditiva acima de 90 dB). (Santos; Martinho 2005)

\subsection{O Diagnóstico da Deficiência Auditiva}

O processo de diagnóstico da deficiência auditiva em crianças, geralmente inicia-se com a percepção dos familiares sobre o comportamento do infante e é confirmado ou não pelo profissional de saúde auditiva.

De acordo com a fonoaudióloga Dantas $(2005)^{3}$, alguns sinais nos comportamentos da criança podem gerar nos pais e familiares uma suspeita de alteração auditiva, como por exemplo, quando a criança dorme com barulhos intensos, não atende quando se chama, quando a criança permanece dormindo, mesmo diante de ruídos ambientais e intensos; balbucio reduzido, quando comparado ao desenvolvimento de crianças ouvintes; e/ou quando a criança não é capaz de atender quando for chamado pelo nome.

A partir da percepção de que algo não está "correto" o familiar busca ajuda profissional para identificar causas e buscar soluções.

\footnotetext{
${ }^{1}$ hipóxia

2 incompatibilidade do fator Rh sanguíneo

${ }^{3}$ Apud Bevilacqua; Moret (2005).
} 


\subsubsection{O Processo Diagnóstico}

O diagnóstico da deficiência auditiva é realizado por um Audiologista, que é um profissional de saúde especializado na identificação, avaliação e (re)habilitação de indivíduos com alterações de audição e/ou alterações de equilíbrio.

A avaliação da audição em crianças é composta por vários exames audiológicos, que segundo Dantas (2005), podem ser divididos em subjetivos e/ou objetivos. O primeiro procedimento subjetivo utilizado na avaliação da audição em crianças é a Anamnese, no qual será realizado um levantamento dos dados relacionados ao histórico de vida da criança, desde a gestação.

É preciso que sejam relatados ao profissional a ocorrência de doenças infecciosas, medicamentos utilizados e avaliações realizadas até o momento, além da existência de familiares com problemas auditivos. Todos os fatos que possam estar relacionados a uma possível alteração no desenvolvimento da criança devem ser descritos.

Segundo procedimento é a Otoscopia, exame físico realizado pelo médico otorrinolaringologista, que permite a avaliação do conduto auditivo externo e da membrana do tímpano. Pode ser realizada com auxilio do Otoscópio 1 (equipamento próprio para o exame) ou do microscópio, que permite uma visão mais detalhada de membrana timpânica. Além de permitir o diagnóstico de várias doenças, tais como, otite externa, otite média, malformações do conduto auditivo, entre outras, a Otoscopia possibilita a remoção de eventuais rolhas de cerúmen, presentes no conduto auditivo e que podem interferir no resultado dos exames audiológicos.

Entre os exames audiológicos realizados em crianças, o autor destaca a Audiometria Tonal, Audiometria em Campo Livre, Audiometria de Respostas Comportamentais, Audiometria de Reforço Visual, Audiometria Lúdica, Audiometria Vocal, Emissões Otoacústicas Evocadas e o Potencial Evocado Auditivo de Tronco Encefálico.

A Audiometria Tonal é um procedimento utilizado durante o diagnóstico das alterações auditivas, na determinação do tipo, grau e configuração audiométrica da deficiência auditiva, contribuindo também na seleção e adaptação de Aparelho de Amplificação Sonora Individual (AASI) e no planejamento da (re) habilitação auditiva.

Este procedimento compreende a medição da audição periférica, a qual tem como objetivo estimar a sensibilidade auditiva para tons puros, em 
diferentes faixas de freqüências. Durante a Audiometria Tonal, é determinado o valor mínimo de intensidade sonora necessário para provocar uma sensação auditiva, ou seja, o limiar auditivo, para cada freqüência especifica de estimulo apresentada.

De acordo com Dantas $(2005)^{4}$ os limiares auditivos podem ser obtidos por via aérea e por via óssea. Na condução aérea, os estímulos auditivos são transmitidos por meio de fontes de ouvido. Na condução por via óssea, os sinais acústicos são transmitidos por meio de um vibrador ósseo, geralmente posicionado atrás da orelha do paciente. A pesquisa limiares tonais por via óssea é realizada apenas quando os limiares auditivos obtidos por via aérea apresentaram alteração.

Em bebês e crianças pequenas, em que não se faz possível a colocação de fones para a obtenção dos limiares auditivos de cada ouvido separadamente (ouvido direito e ouvido esquerdo), a avaliação pode ser realizada com altofalantes, procedimento este denominado Audiometria em Campo Livre. Os resultados obtidos durante a avaliação audiológica em campo livre referem-se à sensibilidade auditiva do melhor ouvido.

A Audiometria em Campo Livre é também utilizada durante o período de indicação, seleção e adaptação do Aparelho de Amplificação Sonora Individual (AASI), para avaliação dos benefícios obtidos com o uso da amplificação.

Do ponto de vista fonoaudiológico, Dantas (2005) ressalta que de acordo com a idade do sujeito avaliado, diferentes técnicas para a realização da Audiometria Tonal podem ser utilizadas. Especialmente na população infantil, a utilização de técnicas específicas para a faixa etária em que a criança se encontra, contribuindo para uma avaliação mais precisa e limiares auditivos mais fidedignos.

Pelo fato da Audiometria Tonal caracterizar-se como uma avaliação subjetiva da audição, isto é, os resultados necessitam da resposta do sujeito avaliado, durante a avaliação em crianças, torna-se de fundamental importância que a mesma esteja bem acomodada, alimentada e atenta durante o teste.

A Audiometria de Respostas Comportamentais é uma avaliação, no qual a criança é avaliada através das habilidades auditivas, observam-se as respostas comportamentais da criança frente ao estímulo sonoro, utilizando sons calibrados, como instrumentos musicais e a voz do examinador que varia de acordo com a idade e com o desenvolvimento neurológico e motor da criança.

\footnotetext{
${ }^{4}$ apud Bevilacqua; Moret (2005)
} 
Geralmente realizada em crianças desde o seu nascimento, compreendendo uma faixa etária de 0 a 24 meses de idade.

A avaliação de Audiometria de Reforço Visual, que é um exame complementar da Audiometria de Repostas Comportamentais, tem como objetivo reforçar qualquer resposta ao estímulo sonoro apresentado pela criança, tais como, sorriso, piscar de olhos, parada de atividade, entre outros. Sendo o exame aplicado em crianças de seis meses a vinte quatro meses de idade, e realizado através do campo livre e/ou com fones.

A Audiometria Lúdica é realizada em crianças entre dois e cinco anos de idade, utilizando brinquedos de interesse da criança, com finalidade de ensiná-la e apresentar uma resposta lúdica a um determinado estímulo sonoro. Sendo nesta avaliação utilizado fones de ouvido ou campo livre.

A Audiometria Vocal, que é uma avaliação realizada a partir dos cinco anos de idade da criança, tem como objetivo determinar o desenvolvimento da aquisição de linguagem e na validação do processo de adaptação de próteses auditivas. Os resultados observados durante a avaliação contribuem para a confirmação dos limiares auditivos obtidos na audiometria tonal, no qual fornece medidas diretas da audição para a fala, além de contribuir no processo de seleção para a prótese auditiva.

Dentre os procedimentos objetivos de avaliação audiológica, os fonoaudiólogos citam o Emissões Otoacústicas Evocadas (EOAE) e o Potencial Evocado Auditivo de Tronco Encefálico (PEATE), mais conhecido na área médica e fonoaudiólogica como BERA. No ouvido interno, mais precisamente a cóclea $^{5}$, existem células capazes de produzir energia acústica, ou seja, sons. Essas células são conhecidas como células ciliadas externas. O som gerado por estas células pode ocorrer espontaneamente ou ser evocadas por um estímulo sonoro. Este som gerado pelas células ciliadas externas é conhecido por emissão otoacústica. Através de um microfone miniaturizado, adaptado a uma sonda, colocado no interior do conduto auditivo externo é possível captar esse som, que é registrado no computador conectado a interface do sistema. (Alvarenga apud Bevilacqua; Moret:2005)

Para a realização deste exame, a criança precisa estar sentada numa cadeira confortável e se pequena esteja no colo dos pais, numa sala com o menor ruído possível e preferencialmente em silêncio. $E$ as crianças com

\footnotetext{
${ }^{5}$ Órgao semelhante a um caracol.
} 
histórico de meningite, rubéola materna, problemas durante 0 parto ${ }^{6}$, toxoplasmose, uso de medicamentos ototóxicos, entre outros, podem apresentar deficiência auditiva por lesão na cóclea, incluindo células ciliadas externas. Contudo, se a criança apresenta perda de audição por alteração em outras estruturas do sistema auditivo que não a cóclea, por exemplo, do nervo auditivo, o diagnostico é Neuropatia Auditiva, nesses casos as EOA estão presentes.

O Potencial Evocado Auditivo de Tronco Encefálico representa a atividade elétrica que ocorre no nervo auditivo e tronco encefálico quando o som é percebido na cóclea. A atividade elétrica que ocorre no sistema auditivo permite que o que escutamos na cóclea seja transmitido para o cérebro, onde ocorre a compreensão deste som. É indicado que o exame seja realizado com a criança dormindo, após a orientação do examinador para os pais, a criança dorme por meio da indução do sono natural, porém em crianças agitadas, se faz necessário a sedação, com acompanhamento médico. A aplicação do PEATE é pertinente em crianças que não conseguem responder adequadamente a Audiometria Tonal liminar, em indivíduos adultos simuladores de deficiência auditiva ou simplesmente para completar e confirmar o diagnóstico audiológico. Sendo que o PEATE é um teste do funcionamento do sistema auditivo.

Contudo, é através desses procedimentos descritos acima que se pode chegar a um diagnóstico preciso e validados, no qual é fundamental a presença dos pais e a cooperação destes. O momento da descoberta de um diagnóstico de deficiência auditiva é bastante complexo e delicado. Durante a realização da bateria de exames, é válido ressaltar a importância do investimento dos pais e do desgaste físico e emocional a que são submetidos seus filhos na realização de exames. Neste momento os pais percebem que precisam de ajuda profissional. Posterior ao recebimento do diagnóstico, muitos pais aparentam estar desorientados. As expectativas geradas pelos pais em torno do diagnóstico são visíveis.

\subsubsection{O Recebimento do Diagnóstico pelos Familiares}

O momento da confirmação do diagnóstico pode ser definido como sendo um golpe pessoal, no qual os pais sentem a necessidade de encontrar uma causa para deficiência auditiva do filho.

\footnotetext{
${ }^{6}$ falta de oxigenação, parto demorado, etc.
} 
De acordo com Demetrio $(2005)^{7}$ os pais ao receberem o diagnóstico podem apresentar, além de um estado de choque, alguns sentimentos, tais como, a raiva, culpa, vergonha, autocomiseração, projeção, padrões de dependência mútua e sentimentos contraditórios, como medo, incapacidade, isolamento, inadequação, frustração, depressão, vulnerabilidade, resistência, afirmação e aceitação.

Para o autor alguns pais ficam incapacitados para processar qualquer informação recebida, em estado de choque, sentindo- se descrente perante a suspeita da surdez. Por sua vez, sentem se também frustrados, sentindo raiva, ódio, impotência e culpa por sentirem responsáveis pela deficiência auditiva.

"Aliados aos sentimentos de culpa podem surgir um problema ainda maior. Alguns pais passam a rejeitar o fato e, consequentemente, o filho deficiente, ao julgarem que este ocupou o lugar daquela criança com a qual eles sonharam e desejarem durante toda gravidez. Obviamente, referidas reações também são geradas pela frustração de um sonho, pelo conflito, diante da incapacidade de lidar com a criança e impotência diante dos problemas". (Demetrio apud Bevilacqua; Moret 2005)

Sinônimo de amor para os pais, mas que pode limitar o desempenho da criança tornando-se menos independente, a superproteção é um sentimento no qual se caracteriza através de comportamentos de atenção e dedicação excessiva dos pais. Pais de crianças com necessidades especiais tendem a ser mais permissivos para não serem rotulados de negligentes e intolerantes, necessitando se de provar a sim mesmo e aos outros que são bons pais.

A vergonha surge frente a reação que os pais possam ter do olhar dos outros; do que os outros irão pensar frente aos comportamentos inadequados da criança. Sentimentos de compaixão, como a autocomiseração é freqüente, como os de projeção, que muitos pais tendem a responsabilizar alguém, como os outros filhos, cônjuge e profissionais, frente à situação ameaçadora do qual enfrenta. Pelo fato da criança portadora de deficiência, os pais podem apresentar cuidados exagerados e inadequados, como padrões de dependência mútua.

O autor destaca também os sentimentos contraditórios, como medo pelo desconhecido, do novo e pela confirmação da deficiência; como o sentimento de incapacidade, por não preverem a deficiência, se julgando incapazes nas suas funções de pais. Sentimentos voltados para família, sentimentos de abandono,

\footnotetext{
${ }^{7}$ apud Bevilacqua; Moret (2005).
} 
de que são diferentes, apresentando isolamento social. As famílias costumam apresentar vulnerabilidade diante da deficiência, desencadeando projeção de sentimentos, rejeição da criança, estresse, depressão e desintegração familiar.

No período de afirmação, os pais estão prontos para admitir ao mundo que tem uma criança deficiente auditiva e começam a trabalhar ativamente por todas as crianças surdas. Em seguida, surge o estagio da aceitação, no qual os pais colocam a surdez em perspectiva para eles próprios, sendo mais um aspecto de suas vidas. Este estágio é também conhecido como ação construtiva, no qual os pais buscam ajuda, informações, falam claramente sobre o problema, adequamse as situações, traçando novos objetivos e valores.

Contudo, Demetrio $(2005)^{8}$ ressalta que esses sentimentos são peculiares a cada família. E que aceitar a criança com suas limitações implica em dar a ela possibilidades de ter um bom desenvolvimento emocional, através da interação recíproca dos pais para que haja o estabelecimento de segurança e para que ambos iniciem e mantenham esta relação.

\subsection{Os Prognósticos na deficiência auditiva}

A presença de uma perda auditiva pode acarretar serias conseqüências para o desenvolvimento de fala e aprendizado. As conseqüências da deficiência auditiva na vida de uma criança são amplas e devastadoras, principalmente quando a deficiência auditiva é de grau severo ou de grau profundo. A privação sensorial auditiva nos primeiros anos de vida impede, ou dificulta, a aquisição da linguagem oral, acarretando dificuldades no convívio familiar e social, no desempenho escolar e na fase adulta podendo surgir dificuldades na profissionalização.

Um recurso de extrema importância para a reabilitação do deficiente auditivo é o Aparelho de Amplificação Sonora Individual (AASI). Este Aparelho de Amplificação Sonora Individual tem como função captar sons, amplificá-los e conduzi-los à orelha do portador de deficiência auditiva.

O uso do Aparelho de Amplificação Sonora Individual representa uma grande chance de modificar os rumos da relação da criança deficiente auditiva com o meio que vive. Porém, para estar bem adaptado, o AASI deve propiciar benefícios aos usuários, no qual quando se fala de benefícios, é estar relacionado como sendo algo que promove ou aumenta bem estar. (Boechat 2003)

\footnotetext{
${ }^{8}$ apud Bevilcqua; Moret (2005).
} 
De acordo com Bucuvic; lorio (2004) é de fundamental importância que a avaliação proporcionado pelo AASI, a fim de ser benéfica, sejam aplicados questionários de auto- avaliação, buscando analisar as dificuldades auditivas frente às diferentes situações de comunicação, ao indicar modificações, avaliar o tratamento e propor mudanças, ao minimizar os efeitos deletérios da perda auditiva na vida pessoal e social do indivíduo.

Almeida; Taguchi (2004) afirmam que os questionários de auto avaliação também possibilitam uma análise do aspecto emocional da perda da audição.

Nas ultimas décadas houve muitos avanços na tecnologia dos aparelhos de amplificação sonora individuais, porém para um grupo de crianças com deficiência auditiva severa e/ou profunda, esses avanços não convergem, suficientemente, para melhora na percepção dos sons da fala. Atualmente, os sistemas de Implante Cocleares Multicanais constituem-se como uma importante alternativa de tratamento para este grupo de crianças. Os Implantes Cocleares revolucionaram o tratamento das deficiências auditivas, uma vez que permitem a percepção dos sons da fala de maneira mais eficaz, segundo Moret (2005).

A autora ainda afirma que o implante coclear, conhecido também como ouvido biônico, é um tratamento cirúrgico na deficiência auditiva, que requer avaliação criteriosa na seleção de crianças candidatas e acompanhamentos póscirúrgico rigoroso, tanto no que se refere aos procedimentos de ativação e mapeamento dos eletrodos, avaliação audiológica e complementares, como também na realização da terapia fonoaudiológica especializada.

O implante coclear é um dispositivo eletrônico composto por um componente externo e outro interno. O componente interno, que contém um receptor e um feixe de eletrodos, é colocado na parte interna do ouvido por meio de cirurgia. O sistema é ligado quando a parte externa, que contém um processador de fala, um microfone e uma antena transmissora, é colocada no paciente, ativando o sistema de implante coclear com auxílio de uma interface conectada ao computador.

Moret (2005) ressalta que os implantes cocleares permitem a percepção dos sons da fala, de modo que a criança implantada possa extrair e abstrair auditivamente as pistas lingüísticas dos modelos de linguagem ao seu redor. A habilitação da criança deficiente auditiva usuária de implante coclear tem seu alicerce nos princípios de reabilitação auditiva, a qual é intervenção que prioriza a alteração primária da criança: 
a audição. E o objetivo da reabilitação auditiva é auxiliar a criança a aprender a falar, integrando a audição a sua personalidade.

Um dos modelos de atendimento à criança deficiente auditiva é a Abordagem Auri- Oral, na qual o conceito de reabilitação auditiva esta fortemente estabelecido.Os princípios básicos da Abordagem Auri- Oral foram redefinidos a partir dos princípios básicos da audiologia educacional descritos por Pollack em 1970. É fundamental compreender que a habilitação da criança deficiente auditiva inicia-se logo após o diagnóstico, pois quanto mais jovem a criança iniciar o tratamento, mais cedo terá a possibilidade de alcançar resultados benéficos de audição e linguagem, isto ocorre tanto para a criança usuária de aparelho de amplificação sonora individual como para a criança usuária de implante coclear. (Moret: 2005)

Como princípios básicos da Abordagem Auri-Oral temos: a detecção precoce da deficiência auditiva e o encaminhamento da criança o mais cedo possível para o tratamento; a indicação e a adaptação do aparelho de amplificação sonora individual (AASI) logo após o diagnóstico; 0 desenvolvimento do feedback acústico- articulatório9 (ouvir sua própria voz) para o monitoramento da fala; a aquisição da linguagem oral e o desenvolvimento da função auditiva e a integração da audição de acordo com a personalidade da criança. Propõe-se que a reabilitação auditiva das crianças implantadas siga os princípios da Abordagem Auri- Oral.

O implante coclear, embora um método cirúrgico eficaz, por si só não conduz a criança ao êxito pleno na habilitação. Além de estar sujeita aos princípios básicos da audiologia educacional mencionados acima, a habilitação da criança implantada ainda depende de vários fatores, como a criança tem que estar adaptada num período de um ano o Aparelho de Amplificação Sonora Individual, e que esteja respondendo aos estímulos sonoros. (Moret: 2005)

Estes atributos e requisitos serão fundamentais para o sucesso da habilitação da criança implantada, que significa uma criança compreendendo a linguagem oral e falando fluentemente a sua língua.

No Brasil, a avaliação da criança candidata ao implante coclear é criteriosa, multifatorial, com critérios de seleção pré- determinados para otimizar os resultados, estes critérios são amplamente discutidos por um grupo de médicos otorrinolaringologistas e fonoaudiólogos que atuam com pacientes implantados por Centros Especializados e Hospitais credenciados ao Programa de Implante Coclear. 
Uma das principais diferenças entre a criança implantada e a criança que usa AASI é a possibilidade da criança implantada apreender incidentalmente. A apreensão incidental significa a criança adquirir e se apropriar da linguagem oral situações naturais, espontâneas e informais vivenciadas em seu ambiente. Com isto, possibilita a criança no mundo uma forma diferenciada como antes não era percebido.

\subsection{RECEBENDO UM PORTADOR DE DEFICIENCIA AUDITIVA}

\subsection{O Estigma de um Surdo}

Estigma, em nossa atualidade, é considerado algo representativo como mal; ameaçador para sociedade, isto é, uma identidade deteriorada por uma ação social. $O$ indivíduo estigmatizado, é alguém que demonstra pertencer a uma categoria com atributos incomuns ou diferentes e é pouco aceito pelo grupo social.

Segundo Goffman (1963), um estigma é a relação entre o atributo e o estereótipo, possui um estigma o sujeito que poderia ser recebido na relação social, mas que por um traço é excluído. O estigma não é um atributo pessoal, mas uma forma de designação social e a análise de sua relação com a identidade social de cada um.

O estigma de um surdo está relacionado aos aspectos sobre a posiçãosujeito que se inscreveu ao surdo. Há cerca de 4000 anos atrás, na era egípcia, a posição de sujeito ocupada pelo surdo não seria a mesma de um humano, por ele não falar e por ser incapaz de aprender. Para os romanos, a discussão em torno de sua posição- sujeito era determinada pelo fato de eles terem uma formação imaginária, segundo a qual, os surdos não tinham possibilidade de desenvolvimento moral e intelectual (Lima apud Costa 2010).

Com base em Benvenuto (2005) ${ }^{9}$, a figura da surdez era confusamente assemelhada a da loucura, e os surdos era adotados, no século $\mathrm{VI}$, pelas congregações religiosas que seguiam a regra do silêncio de Saint Benoit, na qual os monges se comunicavam por meio de signos. Pela ausência da comunicação oral, a posição sujeito surdo se aloca como fora do universo.

${ }^{9}$ apud Santos (2005). 
Segundo Lima $(2010)^{10}$, até o século XV, o mundo não encarava o sujeito surdo como um ser capaz. Logo, a posição-sujeito que cabia ao surdo era a de incapaz de se desenvolver moralmente e intelectual, de se expressar oralmente, sendo incapaz de expressar sentimentos ou qualquer pensamento. Sendo assim, o surdo não dispunha de nenhum tipo de acesso à educação, no qual o acesso só começou a existir a partir do século XVI.

$\mathrm{O}$ autor ressalta que a partir do século $\mathrm{XVI}$, primeiramente através de iniciativas de ensino isoladas e posteriormente institucionalizadas, a educação dos surdos passou a dar-lhes uma posição de sujeito em processo de deslocamento. O sujeito surdo passa a ser olhado como ato a linguagem, capaz de comunicar-se, de pensar, de expressar sentimentos, um ser moral, não é mais considerado um ser rudimentar, a posição sujeito-surdo é tornada humana. O surdo faz-se presente, através da força da ideologia e de sua formação no processo da historicidade e leva a sociedade a ter novas concepções sobre antigas questões que sempre foram postas a humanidade, a presença do sujeito surdo.

Por meio de uma corrida pela história, Benvenuto (2006) expõe posições que rondaram o sujeito surdo. Ele ocupou, assim, posição-sujeito definida como monstro bestial com semelhança à animalidade por seus gritos e gestos comparados aos dos macacos, violador das leis jurídicas e da natureza até o século XIX. Dentre os séculos XVII ao XIX, a posição do sujeito surdo acontece sob a ótica da ciência e da filosofia como desprovido de linguagem, não era concebida fora da oralidade.

O termo surdo, etimologicamente, é um adjetivo, proveniente do latim, surdu, que não ouve; que não quer ouvir, insensível; que não é sonoro, que não tem eco; fraco; pouco perceptível; mudo, silencioso; surdo-mudo. O silêncio é atribuído ao surdo como condição da surdez, ou seja, a ausência de som é atribuída ao surdo, não por não falar, mas por não ouvir. A distinção principal entre o surdo falante e o ouvinte falante, atribui-se ao fato de o primeiro poder produzir som, mas não ouvi-lo; e temos a falta. A condição de insensível e pouco perceptível relacionam-se aos sentidos. Se o sujeito é privado de um dos cinco sentidos, temos novamente a falta (Machado apud Costa 2010).

O sujeito surdo é considerado anormal exatamente por não ser ouvinte. Segundo Foucalt (2001), a genealogia da anomalia são designadas há três figuras que a constituem: o monstro humano, o indivíduo a ser corrigido e a

\footnotetext{
${ }^{10}$ apud Costa (2010).
} 
criança masturbadora. As duas primeiras imagens encontram-se com as posições- sujeito ocupadas pelo surdo ao longo da história. O monstro humano é uma noção jurídica, ele constitui em sua existência uma violação das leis da sociedade e das leis da natureza, estando no campo "jurídico biológico". O surdo viola as leis da sociedade porque não pode estudar, trabalhar, ser economicamente ativo, ser cidadão conforme o padrão de normalidade então estabelecido. Ele também viola as leis da natureza porque um de seus cinco sentidos, e em alguns casos, dois, não desempenha a função para a qual foi criada.

Para o autor, a figura de anormal, provinda do século XVIII, arma uma arapuca para a lei, porque é capaz de suscitar violência, vontade de supressão, cuidados médicos ou piedade, conforme evidenciado historicamente, tornandose primeiro equívoco da lei. O segundo equívoco acontece no decorrer do século XIX, que advém do princípio de inteligibilidade tautológica.

Segundo Costa (2010) o primeiro a declarar o surdo como capaz de pensar e de ser ensinado foi Girolamo Cardano, em 1579, no qual ele fez um método de associação de figuras desenhadas. O sucesso se deu devido a sua percepção de dar ao surdo à possibilidade de elaboração de conceitos.

$\mathrm{Na}$ expressão de tão variadas dadas por alguns autores às posiçõessujeito ocupadas pelo surdo, através dos tempos, há algo que se impõe como característicos o sujeito ser surdo, como imagem de um surdo não humanizado ou a figura humana da natureza inferior, não aceita e não compreendida pela sociedade que busca figuras para representar este sujeito.

\subsection{Expectativas e Sentimentos dos Familiares frente à Deficiência Auditiva}

A palavra expectativa é derivada do verbo latim exspectare, sendo assim, sinônimo de espera, aguardo e esperança, vocábulos que fama de esperança.

Nos meses que se segue a concepção, a família se prepara para a chegada do bebê; já o considera pertencente ao mundo mesmo antes de seu nascimento biológico: ele recebe um nome, tem um quarto e o rosto desenhado nos sonhos dos pais.

O período de nove meses gestacionais traz à tona todas as expectativas sobre o filho, até então restritas ao universo imaginário feminino. Segundo a psicóloga Laura Cavalcanti (2008), o bebê é revestido pelo imaginário que povoa 
o ideal de criança dos pais e familiares, mas também é abrigado por um lugar simbólico, marca das leis que estabelecem aquilo que é propriamente humano que antecipa o terreno em que poderá nascer um sujeito sempre oscilante entre suas vontades conscientes e seus desejos inconscientes.

Spitz (1958) ressalta que desde o início de vida há uma imensa ligação entre o bebê e sua mãe, tanto física quanto psíquica. Esta ligação vai se transformando ao longo do desenvolvimento, ficando cada vez mais permeada pela comunicação intermediada por signos e sinais.

Contudo, a psicóloga Yamada ${ }^{11}$ (2005) relata que na chegada da criança portadora de deficiência auditiva todos os sonhos e expectativas desmoronam quando os pais assim recebem o diagnóstico.

\begin{abstract}
"Sentida como um fardo, a criança desperta grandes emoções nos pais: alegria e esperança misturam-se com preocupação culpa e dúvida. Os sentimentos são conflituosos e a família vivencia o momentos de crise, buscando um meio de se adequar a nova realidade". (Yamada, 2005:271)
\end{abstract}

Os pais defrontam com a frustração de lidar com a situação em que aquele ser que era valorado e desejado, até então, não é exatamente o que esperavam. Experienciam a perda dos sonhos, vivenciam o choque e o medo diante da deficiência, bem como a dor e a ansiedade de imaginar as suas implicações futuras. Podem sentir-se culpados, acreditar que fizeram algo errado para que isso acontecesse e isso os leva a auto- recriminação e auto- censura, posturas que, ao longo do tempo, afetam a criança, reduzindo sua auto-estima e valorização pessoal. (Yamada, 2005)

Furtado (2001) afirma que o sofrimento dos pais, ao saberem que seu filho é portador de deficiência auditiva e/ou surdo, está diretamente relacionado a fatores sociais, ou seja, aos conceitos estabelecidos pela sociedade, de normal, anormal, feio, bonito etc. Os pais sabem que terão de enfrentar uma sociedade preconceituosa, que tende a considerar as pessoas diferentes, incapazes, inferiores, precisamente deixando-as a margem, excluídas.

A família é o primeiro grupo social do qual a criança participará. Portanto, a visão dessa família quanto à surdez e suas implicações são de grande importância no comportamento social da criança.

Minunchin (1988) descreve que a família é considerada um sistema que se adaptam as diferentes exigências das diversas fases do seu desenvolvimento. $A$

\footnotetext{
${ }^{11}$ apud Bevilacqua; Moret2005
} 
família é vista como um todo coeso, inseparável e interdependente, no qual todas as suas partes estão relacionadas. Portanto, cada comportamento, ou sua mudança em um de seus membros afeta o outro.

Segundo Carvalho ${ }^{12}$ (2004), "ser diferente é nossa condição humana". Nós humanos pensamos de formas diferentes, aprendemos o mundo de formas diferentes e consequentemente, agimos também de formas diferentes. $E$ isso independe de querermos ou não, mas a verdade é que somos diferentes.

A autora afirma que pessoas significamente diferentes geram impacto no "olhar" do outro, dito normal, provocando: sentimentos de comiseração, com diversas manifestações de piedade, caridade ou tolerância, seja porque o diferente é cego, surdo, deficiente mental, deficiente físico, autista, ou deficiente múltiplo. Movimentos de cunho filantrópico e assistencialista, pouco ou nada emancipatórios das pessoas com deficiência, pois não lhes confere independência e autonomia.

Segundo Demetrio (2005) a reação da família depende da sua estrutura, recursos para lidar com o desafio da crise e habilidade para lidar com alguns sentimentos. O sentimento de negação surge logo após a confirmação do diagnóstico, movida pelas forças sociais e culturais da família.

"O sentimento de negação é um mecanismo de defesa, na qual o indivíduo é mobilizado diante de um sinal de perigo, que desencadeia uma série de mecanismos repressores que impedirão a vivencia de fatos dolorosos, nos quais o organismo não está pronto para suportar".

(Fiori apud Rappaport; 1981)

Para o autor negar a deficiência da criança é um dos padrões de reação que surge quando o diagnóstico é confirmado. A negação pode ocorrer em diversas fases do processo e os pais podem considerar, erroneamente, 0 problema da surdez como uma tendência a falar tarde, mimo ou teimosia. Também, podem rejeitar o diagnóstico buscando outros médicos e atribuindo os resultados dos exames a uma falha dos equipamentos.

A negação é provavelmente o primeiro sentimento apresentando pelos pais dentro do processo de frustração. O processo de negação é um processo ativo, onde mudanças podem ocorrer; é quando os pais se informam e buscam forças, mesmo negando a situação.

\footnotetext{
12 apud Furtado 2004
} 
Entretanto, a atitude da família, expectativa e o grau de apoio dado, afetarão com maior ou menor probabilidade o desenvolvimento da criança deficiente auditiva e sua aceitação no ambiente familiar, escolar e social. (Demetrio:2005)

\subsection{A comunicação do portador de deficiência auditiva}

A comunicação é a forma que o homem possui para afirmar-se perante a vida e revelar-se ao mundo. $\mathrm{Na}$ arte de falar, escrever ou ouvir estabelecem-se tomadas de consciência, busca de caminhos, descobertas de novos valores. A comunicação é o instrumento pelo qual nos relacionamos, ou seja, é o instrumento de expressão de nosso interior do que pensamos, do que acreditamos ao(s) outro(s).

Segundo Melo (1970), o vocábulo comunicação vem do latim, communis, comum, isto é, aquele que introduz uma idéia de comunhão, comunidade. $O$ autor ressalta que, quando comunicamos, tratamos de estabelecer uma comunidade, ou seja, compartilhamos uma informação, uma idéia, uma atitude.

"A linguagem é um sistema de comunicação natural ou artificial, humano ou não humano. Assim, podemos nos referir à linguagem corporal (humana), às expressões faciais, às reações de nosso organismo (tanto aos estímulos do meio, como de nosso pensamento ou, mesmo, dos aspectos Fisiológicos), à linguagem de outros animais, aos sinais de trânsito, à música, à maneira de nos vestirmos, à pintura, enfim todos os meios de comunicação, sejam cognitivos (internos), socioculturais (relativos ao meio) ou da natureza, como um todo". (Fernandes: 1998).

$\mathrm{Na}$ atualidade, temos a consciência da importância da comunicação em nossa vida tanto do ponto de vista biológico, pedagógico, histórico, sociológico, antropológico como psicológico. Comunicar é transmitir a alguém uma mensagem através de uma linguagem.

Vygotsky (apud Jobim e Souza 2010) ressalta que o uso da linguagem se constitui na condição mais importante do desenvolvimento das estruturas psicológicas superiores (a consciência) da criança.

Para o autor a linguagem se constitui a partir do nascimento, pois, os adultos não falam somente entre si, mas com a criança. Nesta fase, o adulto, através da linguagem, chama a atenção da criança para os objetos, ações ou pessoas, e estão desta forma, possibilitando a organização de sua percepção visual e auditiva. 
A linguagem humana vai além das palavras proferidas, pois é atravessada por rupturas na fala, por tropeços de linguagem e pelos silêncios, mas também pela entonação, pelos gestos, pelas expressões e pelo olhar. (Bevilacqua; Moret; 2005). O que nos leva a considerar que o portador de deficiência auditiva encontrará outras formas de linguagem.

\subsubsection{Desenvolvimento da Linguagem na Criança Portadora de Deficiência Auditiva}

A principal conseqüência para os portadores de deficiência auditiva é no desenvolvimento da linguagem e da fala. $O$ desenvolvimento deste processo incidirá em todo o seu processo de aprendizagem.

O desenvolvimento da linguagem nas crianças não ocorre de maneira semelhante, em crianças portadoras de deficiência auditiva há singularidades em que além dos fatores ambientais, psíquicos entre outros, deve-se também levar em consideração o tipo e o grau da perda auditiva, a época do seu diagnóstico, aquisição dos aparelhos auditivos, aspectos intelectuais, emocionais e atitude familiar. (Bevilacqua:2005)

Vygotsk (1997) afirma que a criança que possui um déficit sensorial não se desenvolve menos que as outras, apenas de uma forma diferente, apropriandose do sentido de maneira própria e inerente a sua dificuldade.

Em seu trabalho clínico, Maria Estella Crididio Justos (2005) ${ }^{13}$ observou que as etapas iniciais de desenvolvimento de linguagem do deficiente auditivo acompanham as etapas de uma criança ouvinte, não considerando as idades cronológicas.

As conseqüências de determinados tipo ou grau de deficiência auditiva acarreta o desenvolvimento da criança. Cada um tem seu próprio ritmo de desenvolvimento e suas habilidades, a despeito da deficiência auditiva. De maneira didática Justos considera as alterações esperadas de acordo com a severidade da deficiência auditiva, conforme descrito abaixo:

- Deficiência leve: se não houver progressão, geralmente não tem efeito significativo no desenvolvimento.

- Deficiência moderada: atrasa o desenvolvimento de fala e linguagem, mas não impede que a criança fale. Se houver intervenção e o aparelho

\footnotetext{
${ }^{13}$ apud Bevilacqua; Moret (2005).
} 
auditivo for utilizado juntamente com o processo terapêutico, a criança irá se desenvolver quase que normalmente.

- Deficiência severa: Pode impedir o desenvolvimento de fala e linguagem, porém se for feito o uso do aparelho auditivo e realizada boa intervenção terapêutica e esforço contínuo da família, a criança poderá receber informações utilizando a audição para o desenvolvimento da fala, linguagem e aprendizado.

- Deficiência profunda: Se não houver intervenção, a fala e a linguagem dificilmente irão se desenvolver. Contudo, se for utilizado aparelho auditivo com intervenção terapêutica intensa, a fala e a linguagem poderão ser desenvolvidas, mas de maneira lenta e com algumas dificuldades. Os portadores da deficiência profunda frequentemente irá se valer da leitura orofacial (leitura labial), ou adquirir a linguagem de sinais.

Civitella (2005) ressalta que a partir da confirmação do diagnóstico da deficiência auditiva, cabe ao profissional envolvido encorajar a mãe para que restabeleça uma atitude de estímulo, conversando com o filho (a) e levando-a entender que este é o melhor caminho para o desenvolvimento amplo da criança.

\subsection{O Papel da Família no Processo de Desenvolvimento da Linguagem e Comunicação}

Para que o desenvolvimento da linguagem no portador de deficiência auditiva seja potencializado faz-se necessário que a família seja ativa neste processo.

As famílias desempenham um papel importante, na verdade um papel definitivo, na escolha do método de comunicação que usarão com seu filho. Os pais devem buscar meios para que ela possa ter acesso a um tipo de linguagem, seja a oralização ou a língua de sinais, que é considerada a língua natural da criança surda. (Rossi 2000)

Segundo Fonseca (2001) os pais necessitam de informação para poder tomar decisão que pode levar semanas ou meses. Esta informação pode ser obtida por meio de diferentes métodos. Por exemplo, os pais podem aprender com vídeos, com diálogos com outros pais, por meio de livros e brochuras e em discussões com os profissionais. Além disso, eles necessitam de tempo para 
observar seu filho e identificar as estratégias de comunicação que eles sentem que de alguma maneira se adaptam as necessidades da criança e dos pais.

Para a autora acima mencionada, o profissional da área de reabilitação tem um papel importante enquanto provedor de tais informações e como observador privilegiado das habilidades de comunicação que emergem a cada instante na criança. Escolher um método de comunicação é um processo dinâmico. As famílias podem ter tempo para obter informação sobre modos de comunicação.

Goldefeld (1998) descreve algumas filosofias educacionais para a comunicação dos surdos, como: o Oralismo, a Comunicação Total e o Bilingüismo.

O Oralismo é caracterizado pela idéia de que a criança deficiente auditiva necessita aprender a língua oral de seu país, para assim integrar-se à comunidade ouvinte. Na filosofia do Oralismo, a aquisição da Língua de Sinais seria prejudicial para o deficiente auditivo, pelo fato de que ao ser exposta a uma língua de fácil acesso, este perderia o interesse em aprender a língua oral. A língua oral é considerada essencial por ser a língua utilizada em seu país.

A comunicação Total surgiu na década de 1960, após a publicação do lingüista William Stockoe, comprovando ser a Língua de Sinais realmente uma língua. Ao contrário do Oralismo, a Comunicação Total não considera a Língua de Sinais prejudicial ao surdo e sim um importante instrumento que deve ser utilizado para facilitação da comunicação do deficiente auditivo. O objetivo principal deste tipo de comunicação é evitar ou minimizar os problemas comunicativos gerados pela surdez. Este método envolve uma variedade de técnicas de comunicação que incluem treinamento auditivo, amplificação, linguagem falada, treino de fala, leitura da fala, linguagem de sinais, alfabeto digital, gestos e pantominas, a ênfase esta em incorporar e combinar qualquer coisa e tudo que funciona para ensinar linguagem e fala para a criança.

No Brasil, a língua brasileira de sinais é a Libras, sendo utilizada pela comunidade dos surdos. A língua brasileira de sinais possui todos os níveis lingüísticos como qualquer língua oral, ou seja, fonológico, morfológico, sintático semântico e pragmático (Brito, 1995; Bellugi et al, 2002).

Cada país possui uma língua de sinais própria, sendo estas línguas independentes das línguas orais utilizadas no país. Assim temos: Língua de Sinais Americana, Língua de Sinais Britânica, Língua Brasileira de Sinais (LIBRAS), Língua de Sinais Sueca, etc. 
O Bilingüismo tem como pressuposto básico a necessidade do surdo ser bilíngüe, ou seja, este deve adquirir como língua materna a Língua de Sinais, que é considerada a língua natural dos surdos, e como segunda língua, a língua oral utilizada em seu país.

"O conceito de Bilingüismo traz em si o conceito de biculturalismo. O surdo domina as duas línguas constitui-se num indivíduo bicultural, já que cada língua reflete a cultura de seus falantes. Isto significa que o surdo brasileiro, além de possuir uma cultura tipicamente brasileira, possui características culturais próprias de sua comunidade, assim como outras minorias que vivem no Brasil, como judeus e imigrantes". (GOLDFELD: 1998)

Em seus estudos Furtado (2008) constatou que muitas famílias ao serem questionadas sobre o método de comunicação de suas crianças surdas, responderam que tudo que possa ajudar o filho é válido. Alguns pais defendem a oralização para seus filhos surdos, alguns argumentaram que em casa e na escola os filhos podem utilizar a linguagem de sinais (LIBRA) para se comunicar, pois assim seriam compreendidos, mas que o mesmo não aconteceria nas ruas, ou seja, na comunidade onde eles são inseridos.

"Pode-se perceber ainda, que além de desejarem que o filho tenha mais facilidade na comunicação com os ouvintes podendo ser mais independentes delas, outro fator é que muitas mães vêem na oralização uma possibilidade de os filhos tornarem-se crianças "normais". (Furtado: 2008; p.89)

A autora ressalta que alguns pais se dedicam a aprender a língua de sinais para tornar fácil a comunicação dos filhos.

Os métodos de comunicação mencionados acima, o mais importante do ponto de vista fonoaudiológico, é que o modo de comunicação será determinado por avaliações dessas variareis: a preferência dos pais, as habilidades da criança e a opinião da equipe de intervenção. É possível que os pais sigam mais do que um método de comunicação nos primeiros anos. Portanto, será essencial para cada programa de intervenção precoce desenvolver critérios objetivos a serem usados como guia de frente a cada decisão (FONSECA, 2001).

Contudo, o desenvolvimento de qualquer das linguagens aprendidas pelas crianças deficientes auditivas precisa de parceria promovido pelo ambiente 
familiar. A parceria dos pais é muito importante, eles precisam de informações precisas e sugestões para conviver com as dificuldades encontradas perante a deficiência. Os pais são considerados agentes transformadores da realidade da criança.

\section{O SUPORTE PROFISSIONAL AOS FAMILIARES DA CRIANÇA SURDA}

\subsection{O Grupo como Suporte}

Desde o nascimento que o ser humano está marcado e marca a sociedade em que se encontra inserido. Nós individuos estamos sempre em interação uns com outros e nosso comportamento individual é influenciado pelo contexto social. Na vida em sociedade o ser humano é integrado em grupos. Cada um de nós pertence, simultaneamente, a vários grupos: família, equipe de trabalho, amigos, escola, etc. Um grupo é o conjunto estruturado de pessoas, definido pelas interrelações que se estabelecem entre os seus membros.

A psicoterapia grupal deu início no ano de 1905, por Joseph Pratt, médico generalista, que através do atendimento a pacientes tuberculosos teve a idéia de criar o método de "classes coletivas", na qual coordenava um grupo para pacientes. Pratt teve como objetivo discutir questões de saúde e respectivas condições de vida, visando a troca de informações entre pacientes, promovendo a melhora no quadro clínico.

Além de Pratt, outros teóricos também contribuiram para a psicoterapia grupal, destacamos: Sigmund Freud (1910), Moreno (1930), Kurt Lewin (1936), Foulkers (1948), Pichon Riviére e W. R. Bion.

Em seu artigo "A psicologia das Massas", Sigmund Freud (1921) descreve de forma mais direta sobre a massa, multidão ou grupo, trazendo contribuições para a psicoterapia grupal. Freud nos mostra que os membros do grupo se ligam através de identificações e que, com isso, ficam sob o efeito da sugestão. O líder ganha total prestígio, tomando uma posição de "Ideal do Eu" para todos os membros (até mesmo os que não o colocam nessa posição, mais tarde serão "sugestionados" para tal fim). No grupo, as pessoas são capazes de fazer coisas 
que nunca teriam imaginado fazer antes, isoladamente. Seus afetos ficam mais exaltados, enquanto a atividade intelectual fica mais rebaixada.

Para o autor, o líder funcionaria como um "pai primitivo". Para existir um líder basta haver pessoas que desejam ser dominadas por um poder ilimitado.

Freud cita, no inicio de seu artigo, o autor de "Psicologia das Multidões", Le Bom, que traz a noção de que há um contágio entre os membros que fazem parte de uma multidão.

\begin{abstract}
"Todo sentimento e ato são contagiosos, a ponto do indivíduo sacrificar facilmente seu interesse pessoal ao interesse coletivo, aptidão contrária a sua natureza e da qual o homem só se torna suscetível quando faz parte de uma multidão". (Freud, Vol IX, p.15)
\end{abstract}

Um dos teóricos mais conhecidos pelo processo grupal, o psicanalista Pichon Riviére, criou a teoria dos grupos operativos a partir dos aportes teóricos psicanalíticos de Melanie Klein e de dinâmica de grupos de Kurt Lewin. Sua formulação de grupos operativos foi considerada a maior contribuição latina americana para uma teoria unificada do funcionamento grupal.

Pichon-Rivière (1998), autor do livro "O Processo Grupal" ressalta que o grupo operativo é uma modalidade técnica que consiste, fundamentalmente, em algumas características: grupo centrado na tarefa, interpretações em verticalidade e horizontalidade, elaboração das ansiedades paranóide e depressiva, ruptura dos estereótipos, reparação das redes de comunicação, superação da resistência à mudança, leitura crítica da realidade, formação de critérios de adaptação ativa, avaliação em termos dos vetores do cone, mobilidade de papéis, unidade de operação (existente- interpretaçãoemergente), enquadramento de tempo e espaço, papéis fixos (coordenador e observador), papeis não fixos (restante dos integrantes).

"O grupo operativo é um grupo centrado na tarefa que tem por finalidade aprender a pensar em termos de resolução das dificuldades criadas e manifestadas no campo grupal, e não no campo de cada um de seus integrantes, o que seria psicanálise individual". (Pichon Riviere: 1998)

Para o autor a dinâmica de um grupo se opera diante da "atitude frente à mudança", na qual é um processo de cura que implica em mudança. A atitude diante da mudança pode ser negativa a qual se classifica como resistência a 
mudança; ou atitude mutante. Diante das situações de mudança surgem os medos básicos. O medo da perda e o medo do ataque. O primeiro é o medo de perder o que já se tem e o segundo é o temor frente ao desconhecido, que pode ser perigoso diante ao manejamento da nova situação.

Os vetores do cone apresentados por Pichon são: a afiliação e pertença, cooperação, pertinência, comunicação, aprendizagem e tele. Eles se interrelacionam dinamicamente.

A afiliação e pertença se estudam o grau de identificação dos membros do grupo entre si e a tarefa. A afiliação é um primeiro grau (mais superficial) de identificação. O sujeito guarda certa distância sem incluir-se totalmente no grupo. A pertença é um segundo grau (mais profundo) que implica encurtar as distâncias. Os membros do grupo que possuem pertença sentem-se fazendo parte do grupo, sentem-se parte de um "nós". E os outros membros sentem-se afiliados, sentem-se mais na relação "eu- eles".

A cooperação estabelece sobre a base de papéis diferenciados (bode expiatório, porta- voz, líder, sabotador). Através da cooperação é que se torna manifesto o caráter interdisciplinar do grupo operativo e o interjogo da verticalidade (historia pessoal do sujeito) e horizontalidade (processo atual que acontece no aqui e agora, na totalidade de seus membros). A cooperação acontece na medida em que os papeis sejam complementares e não suplementares, já que estes últimos papéis levam a uma rivalidade. É através da tarefa que se comprova quem coopera e quem obstaculiza.

A pertinência é um terceiro vetor que surge da realização dos dois vetores anteriores. Consiste no centrar-se do grupo na tarefa (objeto de conhecimento que se torna penetrável através da elaboração das ansiedades básicas que implicam na ruptura da pauta estereotipada), rompendo com os estereótipos, redistribuindo as ansiedades, vencendo a resistência à mudança, elaborando duelos e redistribuindo os papeis. Avalia-se a qualidade da pertinência através da pré- tarefa (técnicas defensivas do grupo, caracterizada pelas diferentes formas de não entrar na tarefa) e da criatividade e da produtividade do grupo e suas aberturas para um projeto ( uma planificação, surgindo quando se consegue uma pertença do grupo).

A comunicação que pode ser verbal e pré-verbal ou gestual. Sendo um lugar privilegiado onde se expressam os transtornos e dificuldades do grupo para enfrentar a tarefa.

A aprendizagem liga-se à comunicação e suas alterações. Para Pichon, toda alteração da comunicação se deve a uma dificuldade na aprendizagem e 
vice-versa. A aprendizagem é obtida pelo somatório de informação dos integrantes do grupo, cumprindo-se, em dado momento, a lei da dialética transformação da quantidade em qualidade.

A tele refere-se ao clima afetivo que prepondera no grupo em diferentes momentos. O termo tele significa uma disposição para agir ao mesmo tempo em que contém o significado de: "a distância". Para Pichon, todo encontro é um reencontro e toda a situação atual é herdeira (ou herdada) de outra situação anterior. A tele configura o clima afetivo que pode ser traduzido como transferência positiva ou negativa do grupo com o coordenador e dos membros entre si.

Contudo, as psicoterapias grupais intervem determinados fatores terapêuticos que se tornam importantes porque explicam como os membros dos grupos se ajudam entre si a mudar de atitude, pensamento e comportamento.

\subsection{Grupo de Acolhimento: "Aprendendo a Ter e a Conviver"}

O Centro de Referência em Saúde Auditiva está localizado em Barra Mansa, no Estado do Rio de Janeiro. A unidade é um serviço de Atenção a Saúde Auditiva de Alta Complexidade, no qual as ações integradas na unidade são de realizar diagnóstico de perdas auditivas e reabilitação em recémnascidos, crianças, jovens, adultos e idosos com perda auditiva; sendo os pacientes atendidos por uma equipe multidisciplinar.

O grupo de Acolhimento "Aprendendo a ter e conviver", teve início em 2008, com o objetivo de proporcionar aos responsáveis pelas crianças com deficiência auditiva um meio de acolher, no qual possam receber informações acerca da surdez, discutir temas do seu cotidiano e compartilhar experiências, sentimentos e atitudes em relação às crianças e a si mesmos. Tendo ainda a oportunidade de estar e conversar com pessoas que estão vivenciando uma situação semelhante, o que geralmente leva uma rápida identificação e sentimentos de solidariedade.

O grupo é formado pelos responsáveis ${ }^{14}$ que trazem as crianças para o atendimento no Centro. É prioritário que para o ingresso do responsável no grupo, a criança esteja realizando terapia fonoaudióloga. As famílias que freqüentam o Centro de Referencia em Saúde Auditiva, em sua grande maioria

\footnotetext{
${ }^{14}$ Pais, avós, tias e irmãos, porém a maioria é formada por mães.
} 
são de classe baixa e moram em bairros distantes, sendo assim a possibilidade do encontro do grupo apenas uma vez por semana, as quartas-feiras.

Um cronograma foi feito para que assim os pais pudessem ser informados sobre as dinâmicas de grupo. No grupo se faz presente uma equipe de profissionais de saúde, como médicos otorrinolaringologistas, pediatra, neurologista, fonoaudiólogo e psicólogo. Dentro das sessões grupais são realizadas oficinas de artes.

O grupo teve como base os teóricos Picho Riviére, Sigmund Freud, Foulkers, Irvin Yalon, entre outros. O objetivo do trabalho do psicólogo junto ao grupo de responsáveis pelas crianças deficientes auditivas, é primeiramente, de acolhimento dos familiares que convivem com as crianças deficientes; além de lidar com a diferença de sua criança. Buscando-se, com isso, uma maior interação entre os familiares e a criança portadora de deficiência auditiva, além de uma maior adesão ao tratamento.

Todas as famílias de crianças portadoras de deficiência auditiva atendidas pelo Centro Auditivo são formadas por ouvintes e a maioria nunca teve contato com surdos. Comumente associam a surdez à incapacidade, à falta, a uma imagem negativa. As famílias chegam ao serviço com pouca ou nenhuma informação relevante sobre surdez, suas causas e conseqüências. Algumas imaginam situações extremas, como, por exemplo, que seus filhos voltarão a ouvir após o "tratamento", ou ainda, que o convívio social é impossível para uma pessoa surda. Com freqüência, esperam dos profissionais de saúde que compõem a equipe do Centro Auditivo muito mais do que esta ao alcance destes.

O grupo pretende ser continente onde os sentimentos, quaisquer que sejam, poderão emergir. Muitos responsáveis chegam ao serviço logo após o diagnóstico, aparentando estar fragilizados, desorientados, com um turbilhão de sentimentos confusos como negação, medo, culpa, revolta ou depressão.

Segundo Pardo $^{15}(2000)$, a família passa por um processo que vai do choque à negação até que compreenda a questão da surdez, superando o impacto que a deficiência tem sobre suas vidas e passando, então, a conceber a idéia de um futuro com menos angústias.

\footnotetext{
15 apud Frota (2000)
} 


\section{Um Retrato do Grupo}

No relato de algumas experiências vivenciadas no Grupo "Aprendendo a ter e a conviver com um deficiente auditivo", várias estratégias foram utilizadas com o intuito de promover a relação família (pais ouvintes) e filhos surdos. A seguir, descreveremos algumas falas exemplificando o trabalho realizado diante de alguns temas propostos, tais como, inclusão escolar, expectativas da família, comunicação entre pais ouvintes e filhos surdos,

Nos primeiros encontros do grupo, foram desenvolvidas técnicas de dinâmica grupal, tendo como foco a apresentação dos membros e identificação.

A inclusão social foi um dos primeiros temas abordados pelo grupo, no qual se percebe a preocupação dos pais, com seus filhos portadores de deficiência auditiva e a possibilidade de rejeição na escola. $O$ medo de que seus filhos sejam ridicularizados ou ignorado é freqüente.

Mãe de uma paciente portadora de deficiência auditiva de 11 anos, comenta:

$$
\text { “(...) sempre }
$$

falo para a minha filha ficar quieta quando não entender o que o professor estiver explicando, pois só assim os outros amigos não vão chamá-la de "surdinha" (...)".

Mãe de um paciente de 13 anos, complementa:

"Os professores não têm paciência, eles gritam achando que 0 meu filho não o escuta."

$$
\text { "Os coleguinhas }
$$

ficam rindo do meu filho, às vezes ele chega em casa chorando e no outro dia não quer ir para escola de aparelho...chega até a esconder o aparelho debaixo do colchão (...)".

\section{"Esses dias meu filho}

me perguntou por que ele é o único surdo na sala de aula".

Para Fonseca (2001), o trabalho psicopedagógico com deficientes auditivos tem sido um desafio marcado por questionamentos diversos, que levaram a um redirecionamento na abordagem da intervenção com vistas a contribuir, de forma mais efetiva, para o processo de educação dessas crianças. 
A tensão se torna maior quando a criança surda se relaciona com pessoas desconhecidas, que não estão familiarizadas com a deficiência auditiva.

Mãe de um paciente de 9 anos, diz:

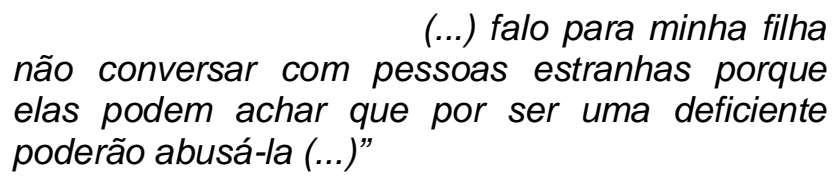

A dificuldade em enfrentar um ambiente social com seus filhos surdos também faz com que seus pais demonstrem insegurança. Avó de um paciente de 10 anos:

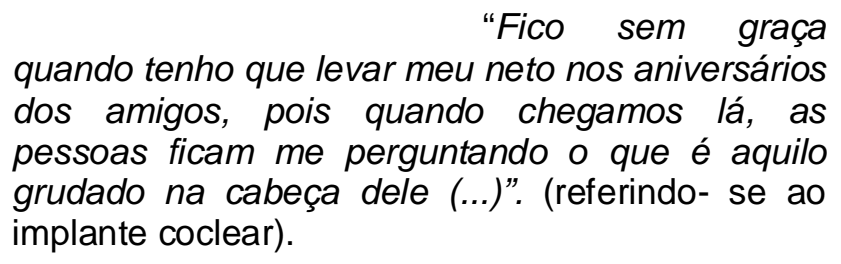

Para Bevilacqua; Moret (2005) a frustração não é um processo estatico, uma vez que os pais das crianças deficientes auditivas podem passar pelos diferentes estados emocionais por vários momentos, ao longo do desenvolvimento.

No decorrer da dinâmica do grupo vários sentimentos como rejeição, negação, medo, angustia e frustração, aparece em varias falas no grupo.

Mãe de um paciente de 9 anos:

"Quando descobri que meu filho era portador de deficiência auditiva achei que fosse castigo de Deus, e logo indaguei por que comigo meu Deus?"

O avô de uma paciente de 8 anos:

“Eu não agüento ver minha filha rejeitando minha neta, ela não tem paciência com a menina, só briga, diz que na cara da menina que não queria tê-la e que é muito trabalhoso ter que levá-la ao Centro toda semana... fico com o coração partido".

Numa fala angustiada, a mãe de uma paciente de 7 anos ressalta:

"Fui ao shopping esses dias e a moça da loja olhou para minha filha e disse: "coitadinha" mãe ela tem que usar esse troço pesado? (...)". 
E a outra mãe conclui:

"Eles acham

que nosso filhos são deficientes mentais, que não entendem (...)".

Por outro lado, muitos pais demonstram aceitação a deficiência auditiva

Mãe de um paciente de 9 anos:

"Eu não deixo que ninguém deboche do meu filho, pois ele é normal a todo mundo".

"Quando se tem alguma dificuldade temos que primeiro ter fé, segundo aceitar as dificuldades e terceiro correr atrás... porque para tudo tem um jeito".

A comunicação estabelecidas entre os pais e os filhos.

Mãe de um paciente de 8 anos:

"Meu

filho não vai aprender a linguagem de sinais não, quero que ele oralize pois assim ele não tera dificuldades no aprendizado".

Mãe de um paciente de 10 anos:

"Todos lá

de casa aprenderam a linguagem de sinais, é muito mais fácil!"

Mãe de um paciente de 11 anos:

"Em casa minha filha fala através da linguagem de sinais e na rua ela usa a linguagem oral...é bom que ela utiliza as duas línguas, e da maneira dela”.

O investimento dos pais é fundamental no processo de (re) habilitação para a criança deficiente auditiva. As famílias com maiores possibilidades de sucesso são aquelas que percebem que sua ação faz diferença no processo educacional e terapêutico. A familia funciona como "agente modificador" da realidade das crianças e os terapeutas como "agente de apoio"(Bevilacqua, 2005)

Mãe de um paciente de 9 anos:

"Quando fiquei sabendo que meu filho era deficiente corri atrás, pesquisei, fui em Bauru, em medicos especializados... e hoje ta ai meu filho implantado!".

Avô paciente de 8 anos: 
"Trago minha neta para fazer terapia fonoaudiológica sim! Vejo resultados e é tão bom!"

O grupo traz a oportunidade de os pais compartilharem suas dificuldades. Através das dinâmicas grupais é perceptível que os pais procurem novos caminhos e alternativas para conviver com a deficiência.

"Hoje, após alguns meses
passados, agradeço muito a todos os
organizadores deste grupo, a todos os pais que
assim como eu, participaram, contribuindo para
que pudéssemos vivenciar novas experiências
com os nossos filhos. Pela oportunidade de
desabafarmos, chorarmos, rirmos... ajudando um
ao outro. Hoje, me considero uma pessoa melhor,
pois vejo que não estou só, e que Deus me deu a
coisa mais linda que é a minha filha. Conversei
com outros pais e vi que não sou a única a passar
por dificuldades, a cada conversa me animo mais,
ajudo mais a minha filha. Fico ansiosa e doida
para chegar o dia do grupo, quantas amizades
foram feitas, quantas trocas. A cada dia amo mais
minha filha e consigo ver nela toda luz que ela nos
trouxe. Adoro a oficina de artes, pois lá vejo que
consigo fazer algo, costurar, bordar, me sinto
viva".
(Relato de uma mãe após o Grupo Aprendendo a ter
e a conviver com um deficiente auditivo).

Lacerda e Caporall (2003) afirmam que um grupo pode apresentar um objetivo comum, mas cada participante apresentará suas idéias, valores e pensamentos, estes constituirão, necessariamente um universo particular, rico em conhecimento e análises.

Contudo, finalizo com uma citação de Fonseca (2005):

"Trabalhar com o deficiente auditivo e suas famílias exigem formação e atualização continuas, abrange quase a totalidade do ser humano, mas a gratificações de acompanhar a trajetória e observar as conquistas de bebes, crianças, jovens e depois adultos é um sentimento profundo e difícil de ser traduzido em palavras". 


\section{CONCLUSÃO}

O presente trabalho ilustrou a importância da interação dos pais frente à deficiência dos filhos. O vínculo entre a criança deficiente auditiva e sua família é um pré-requisito para seu desenvolvimento como um todo. Desde o momento do exame até a confirmação do diagnóstico, a organização psíquica e emocional, da família e da criança, fica comprometida. Muitos pais ficam angustiados e desesperados perante os exames realizados na criança. Ao receberem a confirmação do diagnóstico, sentimentos como o de frustração e incompetência é desencadeado. Porém quando os sentimentos são compartilhados passa a ser mais acessível para os pais enfrentarem a realidade e buscarem por estratégias que facilitem e minimizem as conseqüências da surdez, com o propósito de trazer novos objetivos para seus filhos. O grupo favorece para que muitas experiências e vivências sejam trocadas. No grupo apesar de ser um momento posterior aos exames e diagnóstico, ainda há possibilidade de aceitação com a criança, de como ela é.

Então finalizo exaltando a importância do grupo "Aprendendo a Ter e a Conviver", no qual foi perceptível à integração dos membros, o compartilhamento de experiências, de questionamentos e de sentimentos. 


\section{REFERÊNCIAS BIBLIOGRÁFICAS}

BEVILACQUA, M.C. \& MORET, A.L. Deficiência Auditiva: Conversando com familiares e profissionais de saúde. São José dos Campos: Pulso, 2005.

BRAGA, S.R. Conhecimentos Essenciais para Atender Bem o Paciente com Prótese Auditiva. São José dos Campos: Pulso, 2003.

BUCUVIC, E.C; IÓRIO, M.C.M. Benefícios e dificuldades auditivas: um estudo em novos usuários de prótese auditiva após dois e seis meses de uso. Faro Atual, v. 29, n 7, p. 19-29, 2004.

BUSCAGLIA, L. Os deficientes e seus pais. Rio de Janeiro: Record, 1993.

CAVALCANTI, L. B. A mente do bebê: o fascinante processo de formação do cérebro e da personalidade. Mente e Cérebro, São Paulo: Dueto, $2^{2}$ Ed., p. 7 à 13, 2008.

COSTA, J. P. A Educação do Surdo Ontem e Hoje: Posição Sujeito e Identidade. Campinas, SP: Mercado de Letras, 2010.

FIORI, W.R. Teorias do Desenvolvimento. Volume I.

FONSECA, V.R. Surdez e Deficiência Auditiva: a trajetória da infância à idade adulta. São Paulo: Casa do Psicólogo, 2001.

FOUCAULT, M. Vigiar e punir: nascimento da prisão. Trad. de Raquel Ramalhete. Petrópolis: Vozes, 1987.

. Os anormais: curso no Collège de France (1974-1975). Trad.

Eduardo Brandão, São Paulo: Martins Fontes, 2001.

FURTADO, R.S. Surdez e a Relação Pais-Filhos na Primeira Infância. Canoas: Ulbra, 2008.

FREUD, S. Edição Standard Brasileira das Obras Psicológicas Completas de Sigmund Freud, Rio de Janeiro: Imago, 1969.

. Psicologia de Grupo e Análise do ego (1921), vol XVIII.

FROTA, S. \& GOLDFELD, M. Enfoques em Audiologia e Surdez. São Paulo: AM3 Artes, 2006.

GOFFMAN, E. Estigma: notas sobre a manipulação da identidade deteriorada. Rio de Janeiro: Guanabara, 1998.

GOLDEFELD, M. Fundamentos em Fonoaudiologia. Rio de Janeiro: Guanabara, 1998.

JOBIM \& SOUZA, S. Infância e linguagem: Bakhtin, Vygotsky e Benjamin. Campinas, SP: Papirus, 1994. 
LIMA, M. S. Surdez, bilingüismo e inclusão. Dissertação de Doutorado em Lingüística Aplicada. Campinas: IEL/ Unicamp, 2004.

MELO, J. M. Comunicação social teoria e pesquisa. Petrópolis: Vozes, 1970.

MINUCHIN S. Família, funcionamento e tratamento. Porto Alegre: Artes Médicas, 1988.

MUSIEK, F. E. \& RINTELMANN, W. F. Perspectivas Atuais em Avaliação Auditiva. Barueri, SP: 2001.

PICHON- RIVIERE, E. O Processo Grupal. In: VELLOSO, M. A. São Paulo: Martins Fontes, 2000.

ROESER, J.R. Manual de Consulta Rápida em Audiologia. Rio de Janeiro: Revinter, 2001.

ROSSI, T.R.F. Brincar: um caminho bilíngüe para a mãe da crianca surda. Unicamp. Pesquisa, EPRE/ FCM Brasil, Universidade de Campinas, 2000.

VYGOTSKY, L. Obras escogidas: tomo V. fundamentos da defectologia. Madrid: Portugal Visor, 1997. 